\title{
Fuzzy Pi Adaptive Learning Controller for Controlling the Angle of Attack of an Aircraft
}

\author{
Srinibash Swain \\ Electrical Engineering \\ Synergy Institute of Technology (SIT) \\ Bhubaneswar, India
}

\author{
Partha Sarathi Khuntia \\ Electronics and Telecommunication Engineering \\ Konark Institute of Science and Technology (KIST) \\ Bhubaneswar, India
}

\begin{abstract}
In this paper, a Fuzzy PI Adaptive Learning controller is proposed for a flight control system to control the angle of attack of an aircraft. The proposed controller tracks the reference angle as desired by the pilot of the aircraft. The performance indices are evaluated and the corresponding value is compared with that for the conventional controllers obtained from Zigler Nichols (ZN), Tyreus Luyben (TL) and Extended Skogestad Internal Model Controller (ESIMC). The performance indices such as Mean Square Error (MSE), Integral Absolute Error (IAE) and Integral Absolute Time Error (IATE) are evaluated to verify superiority of one over another.
\end{abstract}

Keywords-Angle of Attack; Interpolation Rule; Performance Indices; Fuzzy PI Adaptive Learning Controller

\section{INTRODUCTION}

An aircraft flies in a 3D space controlled by its control surfaces such as aileron, rudder and elevator. Generally the motion of aircraft is changed by these control surfaces, but the angle of attack of the aircraft is controlled by the deflection of the elevator. Since to control the angle of attack of an aircraft is very crucial, therefore fuzzy controllers are frequently used to offer better and accurate output as compared to conventional controllers $\mathrm{ZN}, \mathrm{TL}$ and ESIMC (Interpolation Rule).

In 1958, W. Gracey [1] summarised about the methods of measuring the angle of attack of an aircraft in a precise manner. C. Grimholt [2] gives an idea of improving the Skogestad Internal Model PI control strategy. M Shamsuzzoha and S. Skogestad [3] discussed about the set-point overshoot method for a closed loop PID controller. S Yordanova and E Haralanova [4] designed and implemented a robust multivariable PI fuzzy controller for an aerodynamic system. F. Dimeas and N. Aspragathos [6] proposed a Fuzzy Learning Variable Admittance Control for a Human Robot system. I.S Baruch and S. Hernandez [7] discussed about a decentralised direct I-term Fuzzy-neural controller for controlling an anaerobic digestion bioprocess system. Lian Ruey-Jing [8] proposed an adaptive self-organising fuzzy sliding mode, Radial Basis Function Neural Network controller for robotic mechanism. S. Kamalasadan and A.A Ghandakly [9] proposed Neural Network based parallel adaptive controller to track the pitch rate of a fighter aircraft. Huang Huazhang and Chung Chi-Yung [10] implemented an adaptive neuro fuzzy Controller for static VAR compensator to damp out the oscillations of wind energy. Guo Lusu and L Parsa [11] designed a Model reference adaptive controller for a five phase IP motor. Dawood Amoozegar [12] proposed about the modelling of a DSTATCOM for stability analysis of the voltage with the help of a fuzzy logic PI current controller. K. Premkumar and B.V. Manikandan [13] designed an Adaptive neuro-fuzzy inference system to control the speed of a brushless DC motor. E.A. Ramadan, M. El-bardini and M.A. Fkirin [14] designed and implemented FPGA to control the speed of a DC motor using an adaptive fuzzy controller. A. Fereidouni, M.A.S. Masoum and M. Moghbel [15] proposed a new adaptive fuzzy PID controller. J. Yoneyama [16] designed a nonlinear control system based on generalised Takagi-Sugeno fuzzy systems.

In this paper, an adaptive fuzzy PI controller is implemented for controlling the angle of attack of an aircraft. Then the performance indices (MSE, ISE \& ITAE) of the aircraft are evaluated and the results are compared with the conventional Zeigler Nichols, Tyreus Luyben and Skogestad Internal Model Control techniques and it was established that the adaptive fuzzy PI controller gives excellent results which improves the performance indices and reduces the error.

\section{ANGLE OF ATTACK CONTROL SYSTEM}

Figure 1 below depicts the block diagram representation of the angle of attack with disturbance and controller. In this diagram input is the elevator deflection and output is the angle of attack.

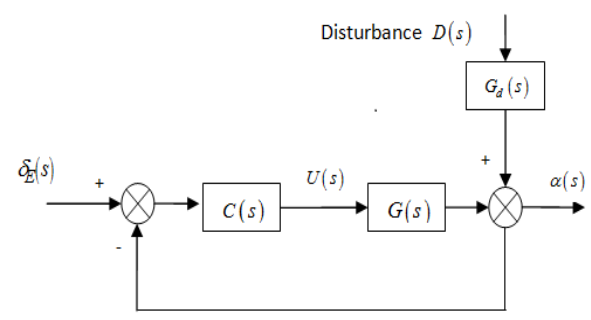

Fig. 1. Angle of attack with disturbance and controller

$G(s)=$ Transfer function of angle of attack

$C(s)=$ Fuzzy PI controller Transfer Function

$G(s)=G_{1}(s)=$ Disturbance

where,

$\delta_{E}(s)=$ The elevator deflection

$\alpha=$ The angle of attack 
Angle of attack is defined as the angle between the chord line of the wing and the relative motion between aircraft and atmosphere. It is controlled by the elevator deflection. Figure 2 below illustrates the angle of attack and the direction of relative wind.

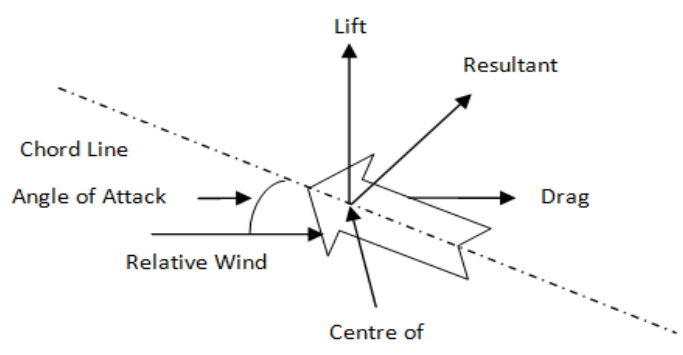

Fig. 2. Angle of attack and the direction of relative wind

Considering the short period approximation (speed of the aircraft $\mathrm{u}=$ constant) the longitudinal dynamics [5] of the aircraft reduces to elevator deflection, then using vector matrix notation, Equation (1) and Equation (2) may be written as

$$
\begin{aligned}
& \dot{w}=Z_{w} w+U_{0} q+Z_{\delta_{E}} \delta_{E} \\
& q=M_{\dot{w}} w+M_{w} \dot{w}+M_{q} q+M_{\delta_{E}} \delta_{E}=\left(M_{\dot{w}}+M_{w} Z_{w}\right) w \\
& +\left(M_{q}+U_{0} M_{w}\right) q+\left(M_{\delta_{E}}+Z_{\delta_{E}} M_{\dot{w}}\right) \delta_{E}
\end{aligned}
$$

If $x=\left[\begin{array}{c}w \\ q\end{array}\right]=$ the state vector and $\mathrm{u}=$ the control vector $=$

$$
\dot{x}=A x+B u
$$

where,

$$
\begin{aligned}
& A=\left[\begin{array}{cc}
Z_{w} & U_{0} \\
\left(M_{w}+M_{\dot{w}} Z_{w}\right) & \left(M_{q}+U_{0} M_{\dot{w}}\right)
\end{array}\right] \\
& B=\left[\begin{array}{c}
Z_{\delta_{E}} \\
M_{\delta_{E}}+Z_{\delta_{E}} M_{\dot{w}}
\end{array}\right]
\end{aligned}
$$

Now

$$
\begin{gathered}
{[s I-A]=s\left[\begin{array}{cc}
1 & 0 \\
0 & 1
\end{array}\right]-\left[\begin{array}{cc}
Z_{w} & U_{0} \\
\left(M_{w}+M_{\dot{w}} Z_{w}\right) & \left(M_{q}+U_{0} M_{\dot{w}}\right)
\end{array}\right]} \\
=\left[\begin{array}{ll}
s & 0 \\
0 & s
\end{array}\right]-\left[\begin{array}{cc}
Z_{w} & U_{0} \\
\left(M_{w}+M_{\dot{w}} Z_{w}\right) & \left(M_{q}+U_{0} M_{\dot{w}}\right)
\end{array}\right] \\
=\left[\begin{array}{cc}
s-Z_{w} & -U_{0} \\
-\left(M_{w}+M_{\dot{w}} Z_{w}\right) & {\left[s-\left(M_{q}+U_{0} M_{\dot{w}}\right)\right.}
\end{array}\right]
\end{gathered}
$$

Again, $\Delta_{s p}(s)=\operatorname{det}[s I-A]=s^{2}+\left[-\left(Z_{w}+M_{q}+U_{0} M_{w}\right)\right] s+\left[Z_{w} M_{q}-U_{0} M_{w}\right]$

$$
=s^{2}+2 \zeta_{s p} \omega_{s p} s+\omega_{s p}^{2}
$$

The transfer function is given by

$$
\frac{w(s)}{\delta_{E}(s)}=\frac{\left(U_{0} M_{\delta_{E}}+M_{q} Z_{\delta_{E}}\right)\left\{1+\frac{Z_{\delta_{E}}}{U_{0} M_{\delta_{E}}-M_{q} Z_{\delta_{E}}} s\right\}}{\Delta_{s p}(s)}=\frac{K_{w}\left(1+s T_{1}\right)}{\Delta_{s p}(s)}
$$

where,

$K_{w}=\left(U_{0} M_{\delta_{E}}+M_{q} Z_{\delta_{E}}\right)_{T_{1}=\frac{Z_{\delta_{E}}}{K_{w}}}$

Again,

$$
\dot{\alpha}=\frac{\dot{w}}{U_{0}} \Rightarrow \alpha(s)=\frac{w(s)}{U_{0}} \Rightarrow w(s)=U_{0} \alpha(s)
$$

From Equation (6) and Equation (7), the transfer functions for angle of attack is given by

$$
\begin{aligned}
& \therefore \frac{\alpha(s)}{\delta_{E}(s)}=\frac{\left(U_{0} M_{\delta_{E}}+M_{q} Z_{\delta_{E}}\right)\left\{1+\frac{Z_{\delta_{E}}}{U_{0} M_{\delta_{E}}-M_{q} Z_{\delta_{E}}} s\right\}}{U_{0} \Delta_{s p}(s)}=\frac{K_{w}\left(1+s T_{1}\right)}{U_{0} \Delta_{s p}(s)} \\
& \Rightarrow \frac{\alpha(s)}{\delta_{E}(s)}=\frac{K_{w}\left(1+s T_{1}\right)}{U_{0} \Delta_{s p}(s)}
\end{aligned}
$$

The above values are the stability derivatives [5] of longitudinal dynamics of FOXTROT aircraft as shown in "Table 1" below.

TABLE I. STABILITY DERIVATIVES OF FOXTROT AIRCRAFT

\begin{tabular}{|c|c|c|}
\hline \multirow{2}{*}{$\begin{array}{c}\text { Stability } \\
\text { Derivatives }\end{array}$} & \multicolumn{2}{|c|}{ Flight Condition(FC) } \\
\hline$U_{0}\left(m s^{-1}\right)$ & 70 & FC-2 \\
\hline$Z_{u}$ & -0.117 & -0.088 \\
\hline$Z_{w}$ & -0.452 & -0.547 \\
\hline$Z_{q}$ & -0.76 & -0.88 \\
\hline$M_{u}$ & 0.0024 & -0.008 \\
\hline$M_{w}$ & -0.006 & -0.03 \\
\hline$M_{\dot{w}}$ & -0.002 & -0.001 \\
\hline$M_{q}$ & -0.317 & -0.487 \\
\hline$X_{\delta_{E}}$ & 1.83 & 0.69 \\
\hline$Z_{\delta_{E}}$ & -2.03 & -15.12 \\
\hline$M_{\delta_{E}}$ & -1.46 & -11.14 \\
\hline
\end{tabular}

The transfer function for both the flight conditions (Flight Condition-1 and Flight Codition-2) are obtained after substituting the values of the stability derivatives mentioned in "Table 1" above. Now the transfer functions are given by

Flight Condition-1

$$
G_{1}(s)=\frac{2.0302 s+102.8}{s^{2}+0.901 s+0.5633}=\frac{3.604 s+182.5}{1.7752 s^{2}+1.5798 s+1}
$$

Flight Condition-2

$$
G_{2}(s)=\frac{15.11 s+0.003027}{s^{2}+1.2989 s+8.216}=\frac{1.84 s+368.5}{0.1217 s^{2}+0.1581 s+1}
$$

\section{CONVENTIONAL PI CONTROLLERS}

The transfer function for PI controller $[\mathrm{C}(\mathrm{s})]$ is given by $\mathrm{C}(\mathrm{s})=\mathrm{K}_{\mathrm{p}}+\left(\mathrm{K}_{\mathrm{i}} / \mathrm{s}\right)$ and the values of $\mathrm{K}_{\mathrm{p}}$ and $\mathrm{K}_{\mathrm{i}}$ are determined by various types of conventional PI controllers, such as Zeigler Nichols, Tyreus Luyben and Extended Skogestad Internal Model Controller and are discussed as follows:

\section{A. Zeigler-Nichols (ZN) PI controller}

In this method, the PI controller [2] parameters $K_{p}$ and $T_{i}$ depends on the value of ultimate gain $\mathrm{K}_{\mathrm{u}}$ and ultimate period 
$\mathrm{P}_{\mathrm{u}}$ for sustained oscillations. The value of PI controller parameters is shown in Table 2 below.

TABLE II. VALUES OF $K_{\mathrm{P}}$ AND $\mathrm{T}_{1}$ FOR ZN CONTROLLER

\begin{tabular}{|c|c|c|}
\hline $\begin{array}{c}\text { PID } \\
\text { Type }\end{array}$ & $K_{p}$ & $T_{i}$ \\
\hline PI & $\frac{k_{u}}{3.2}$ & $2.2 P_{u}$ \\
\hline
\end{tabular}

\section{B. Tyreus-Luyben(TL) PI Controller}

In this type of controller [3], the oscillations are minor and the controller is robust unlike Zeigler Nichols and the tuning parameters $\mathrm{K}_{\mathrm{p}}$, and $\mathrm{T}_{\mathrm{i}}$ are illustrated in the Table 3 below.

TABLE III. VALUES OF $K_{\mathrm{P}}$ AND $\mathrm{T}_{\mathrm{I}}$ FOR TL CONTROLLER

\begin{tabular}{|c|c|c|}
\hline $\begin{array}{c}\text { PID } \\
\text { Type }\end{array}$ & $K_{p}$ & $T_{i}$ \\
\hline PI & $0.45 k_{u}$ & $\frac{P_{u}}{1.2}$ \\
\hline
\end{tabular}

\section{Extended Skogestad Internal Model (ESIMC) PI Controller (Interpolation Rule)}

In this type of controller [2], the values of $\mathrm{K}_{\mathrm{p}}$ and $\mathrm{K}_{\mathrm{i}}$ for proportional and integral controller are given by

$K_{p}=\max \{A, X\}$,

where, $X=B$ for $\zeta \geq 1$ and $X=\zeta B^{\prime}+(1-\zeta) C$ for $\zeta<1$

$K_{i}=\max \{A, X\}$,

where, $X=B$ for $\zeta \geq 1$ and $X=\zeta B^{\prime}+(1-\zeta) C$ for $\zeta<1$

The values of $A, B, B^{\prime}$ and $C$ for proportional and integral controllers are given in Table 4 below.

TABLE IV. The Values of $A, B, B^{\prime}$ And $C$

\begin{tabular}{|c|c|c|}
\hline$A$ & Calculation of $K_{C}$ & Calculation of $K_{I}$ \\
\hline$B$ & $\frac{2 \zeta}{k^{\prime \prime}\left(\tau_{c}+\theta\right) \tau_{0}}$ & $\frac{1}{k^{\prime \prime}\left(\tau_{c}+\theta\right) \tau_{0}^{2}}$ \\
\hline$B^{\prime}$ & $\frac{1+4\left(\tau_{c}+\theta\right)+\frac{\left(\zeta+\sqrt{\zeta^{2}-1}\right)}{\tau_{0}}}{k^{\prime \prime}\left(\tau_{c}+\theta\right)^{2}}$ & $\frac{\left(\zeta+\sqrt{\zeta^{2}-1}\right)}{k^{\prime \prime}\left(\tau_{c}+\theta\right)^{2} \tau_{0}}$ \\
\hline$C$ & $\frac{1+4\left(\tau_{c}+\theta\right)+\frac{\zeta}{\tau_{0}}}{k^{\prime \prime}\left(\tau_{c}+\theta\right)^{2}}$ & $\frac{\zeta}{k^{\prime \prime}\left(\tau_{c}+\theta\right) \tau_{0}}$ \\
\hline$k^{\prime \prime}\left(\tau_{c}+\theta\right)^{2}$ & $\frac{1}{16 k^{\prime \prime}\left(\tau_{c}+\theta\right)^{3}}$ \\
\hline
\end{tabular}

In Table 4 above,

$k^{\prime \prime}=\frac{k}{\tau_{0}^{2}}$

$k=$ The gain $\tau_{0}=\frac{1}{\omega_{n}}$

$\omega_{\mathrm{n}}=$ Natural frequency of oscillation

$\zeta=$ Damping ratio

$\tau_{c}=$ The controller tuning parameter

$\theta=\tau_{0}(1.5+0.5 \zeta)(0.6)^{a}=$ the delay angle

$a=\tau_{0}^{2}$

$B^{\prime}$ is obtained by setting $\sqrt{\zeta-1}=0$ in $B$.

\section{Result Analysis for Conventional Controllers}

The simulations for above three controllers are done by the help of Matlab 7.1. The step response of controller output ' $u$ ' and the system output (angle of attack) ' $y$ ' for three controllers for Flight Condition-1 and Flight Condition-2 with set-point and disturbances are shown in Figures 3 to 6, respectively.

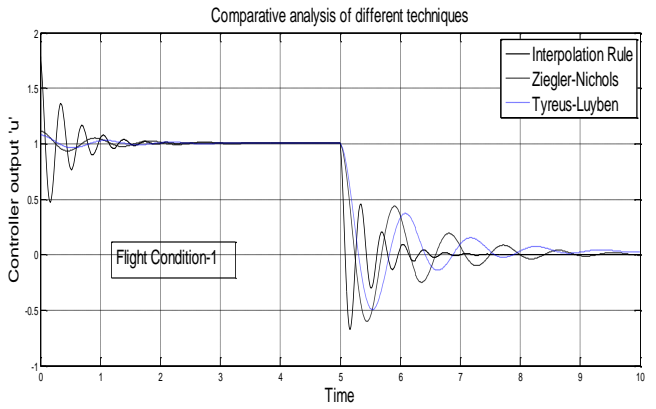

Fig. 3. Step response of ' $u$ ' with set-point and disturbance for flight condition-1

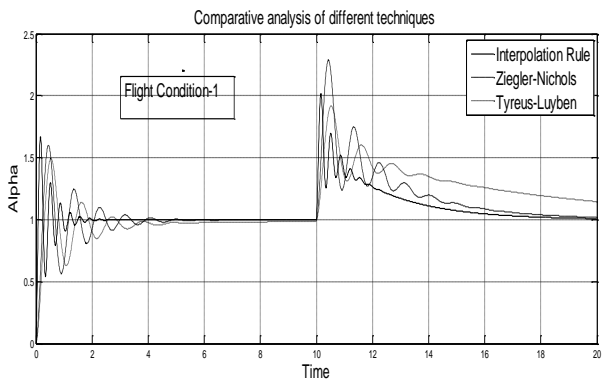

Fig. 4. Step response of ' $y$ ' with set-point and disturbance for flight condition-1

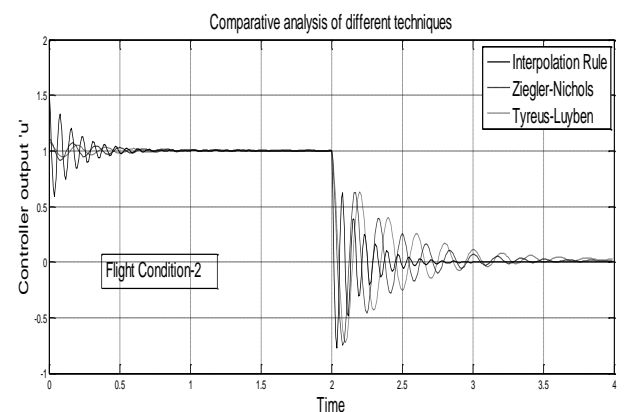

Fig. 5. Step response of ' $u$ ' with set-point and disturbance for flight condition-2 


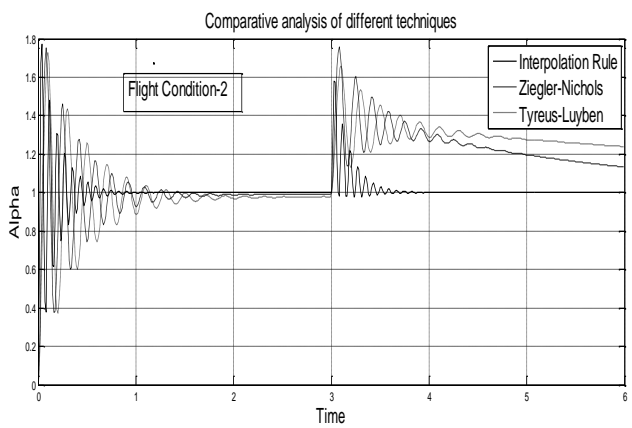

Fig. 6. Step response of ' $y$ ' with set-point and disturbance for flight condition-2

\section{AdAPTIVE FUZZY LEARNING CONTROLLER (AFLC)}

An adaptive Fuzzy PI Controller [6] utilises a learning mechanism for controlling the angle of attack and adjusts the rule base such that the overall system behaves like a reference model. The fuzzy controller improves the stability of a timevariant non-linear system by tuning controller parameters. Figure 7 below shows functional block diagram of the controller.

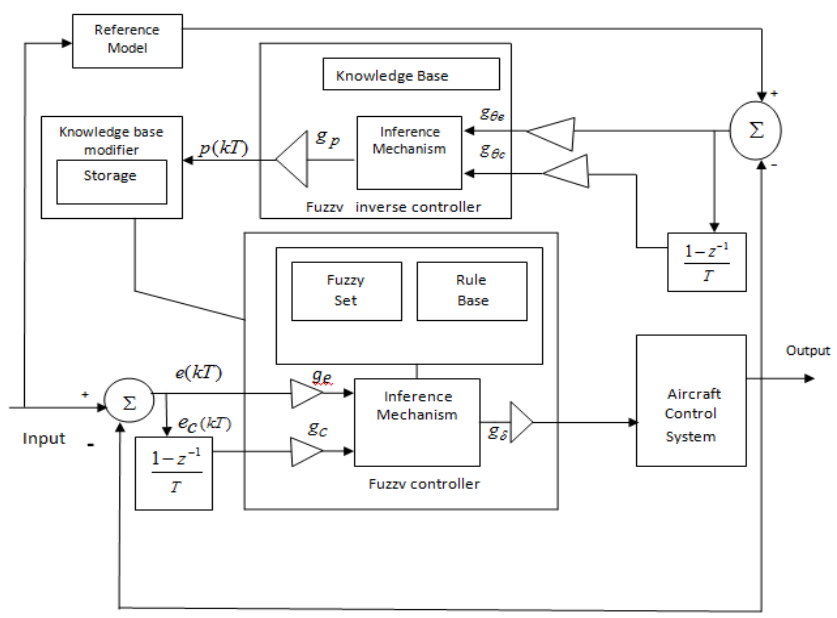

Fig. 7. Functional Block Diagram of Fuzzy Learning Controller

\section{A. Fuzzy Rule Base}

It is nothing but a set of if-then rules according to which the Fuzzy Controller operates to control the angle of attack of an aircraft. The rule base for the present work is shown in Table 5 below.
TABLE V. Rule BASE FOR THE ANGLE OF AtTACK FuZZY MODEL

\begin{tabular}{|c|c|c|c|c|c|c|c|c|c|c|c|c|}
\hline \multirow{2}{*}{\multicolumn{2}{|c|}{$\begin{array}{c}\text { Elevator } \\
\text { Deflection }\end{array}$}} & \multicolumn{11}{|c|}{ Change in Error } \\
\hline & & -5 & -4 & -3 & -2 & -1 & 0 & 1 & 2 & 3 & 4 & 5 \\
\hline \multirow{11}{*}{ Error } & -5 & 5 & 5 & 5 & 5 & 5 & 5 & 4 & 3 & 2 & 1 & 0 \\
\hline & -4 & 5 & 5 & 5 & 5 & 5 & 4 & 3 & 2 & 1 & 0 & -1 \\
\hline & -3 & 5 & 5 & 5 & 5 & 4 & 3 & 2 & 1 & 0 & -1 & -2 \\
\hline & -2 & 5 & 5 & 5 & 4 & 3 & 2 & 1 & 0 & -1 & -2 & -3 \\
\hline & -1 & 5 & 5 & 4 & 3 & 2 & 1 & 0 & -1 & -2 & -3 & -4 \\
\hline & 0 & 5 & 4 & 3 & 2 & 1 & 0 & -1 & -2 & -3 & -4 & -5 \\
\hline & 1 & 4 & 3 & 2 & 1 & 0 & -1 & -2 & -3 & -4 & -5 & -5 \\
\hline & 2 & 3 & 2 & 1 & 0 & -1 & -2 & -3 & -4 & -5 & -5 & -5 \\
\hline & 3 & 2 & 1 & 0 & -1 & -2 & -3 & -4 & -5 & -5 & -5 & -5 \\
\hline & 4 & 1 & 0 & -1 & -2 & -3 & -4 & -5 & -5 & -5 & -5 & -5 \\
\hline & 5 & 0 & -1 & -2 & -3 & -4 & -5 & -5 & -5 & -5 & -5 & -5 \\
\hline
\end{tabular}

\section{B. Fuzzy Membership Functions}

The membership functions characterise the situations for application of the fuzzy rules. In this work the membership functions for input and output are taken into consideration. The membership functions input universe of discourse is assumed to be constant and are not tuned by adaptive controller whereas that for output universe of course are known.

In this work the tuning parameters $\mathrm{g}_{\mathrm{e}}=2 / \pi, \mathrm{g}_{\mathrm{c}}=250$ and $\mathrm{g}_{\mathrm{u}}=8 \pi / 18$ for an output universe of discourse [-1, 1] are triangular in shape with base widths of $0.4 * g_{u}$ and centres at zero are chosen. This choice represents that the fuzzy controller initially knows nothing about how to control the plant so it inputs $\mathrm{u}=0$ to the plant initially. Fuzzy controller input and output membership functions are depicted in following Figures 8 and 9, respectively.

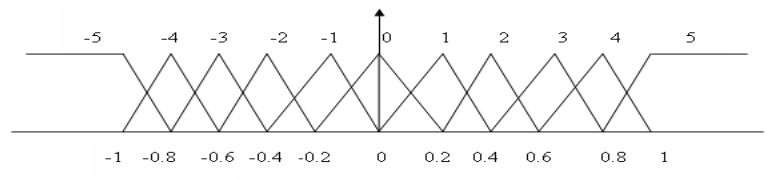

Fig. 8. Fuzzy controller input Membership Function

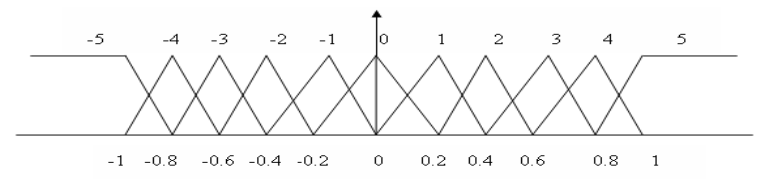

Fig. 9. Fuzzy controller output Membership Function 


\section{The Learning Mechanism}

The rule base of the fuzzy controller is tuned by the learning mechanism to make the close loop system a reference model. The modification of rule base is done according to the output of controller and the reference model. The learning mechanism is divided into two parts. The first part is the fuzzy inverse model and the second part is the rule base modifier. The fuzzy inverse model maps with the change in input required to force the output to zero. In this paper, membership functions for the input universes of discourse are symmetrical triangular-shaped.

\section{Rule Base Modifier}

The rule base of the fuzzy controller can be changed by rule base modifier to force the error of the control action to zero. The input to the fuzzy controller is the error signal and the change in error signal. The rule base can be changed by shifting the centres of the membership functions as depicted in Figure 10 below.

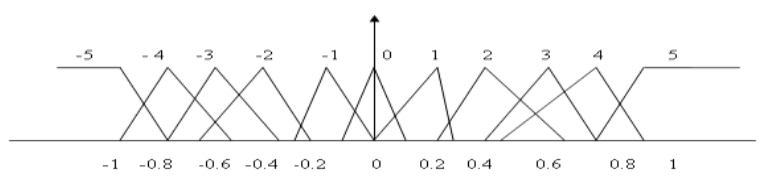

Fig. 10. Shifting of Centers of Membership Functions

\section{E. Simulation Results of the Adaptive Fuzzy Learning Controller (AFLC)}

The simulation is done by using Matlab 7.1. The simulation is done by taking two cases into consideration.

1) Case-I: Simulation without Sensor Noise

2) Case-II: Simulation with Sensor Noise

1) Case-I: Simulation without Sensor Noise: In this case the reference signal is applied for a duration of 40 seconds out of which the first 25 seconds is for FC-1 with a speed of $70 \mathrm{~m} / \mathrm{dssec}$ and the next 15 seconds for FC-2 with a speed of $265 \mathrm{~m} / \mathrm{sec}$. Initially, AFLC has no adaptation but as the flight proceeds the controller gets adapted with changing the centre of membership function.

Figure 11-a depicts the angle of attack and desired angle of attack whereas Figure 11-b shows the elevator deflection i.e. input to the aircraft which is output from the fizzy controller. Similarly, Figure 11-c depicts the Fuzzy inverse model output in which the non-zero values indicates the adaptation. Again, Figure 11-d depicts the error between the actual and desired values whereas Figure 11-e depicts the change in error. Figure 11-f shows the error between angle of attack and the reference model and Figure 11-g shows the corresponding change in error.

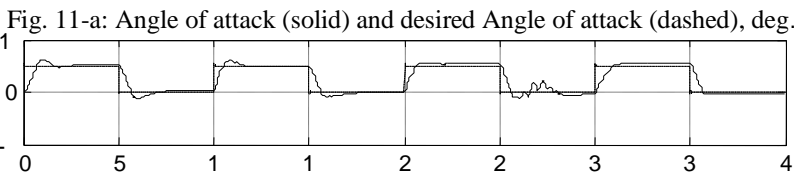

Fig. 11-b: Elevator deflection, output of fuzzy controller (input to the aircraft), deg.

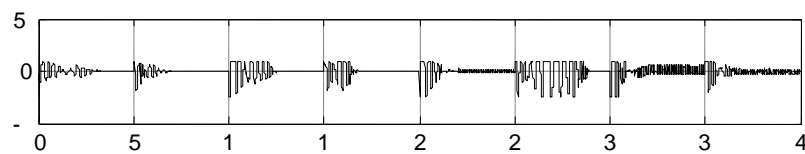

Fig. 11-c: Fuzzy inverse model output (nonzero values indicate adaptation)

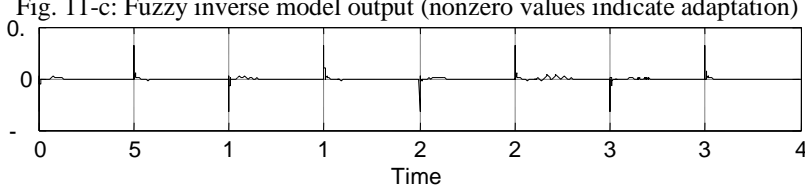

Fig. 11-d: Angle of attack error between Angle of attack and desired Angle of attack, deg.

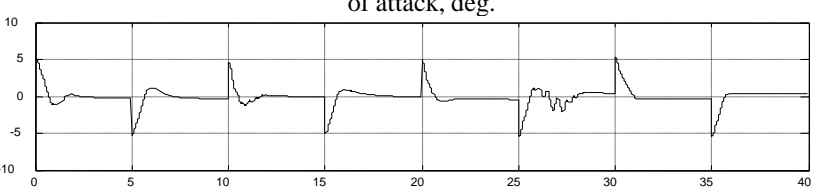

Fig. 11-e: Change in Angle of attack error, deg./sec

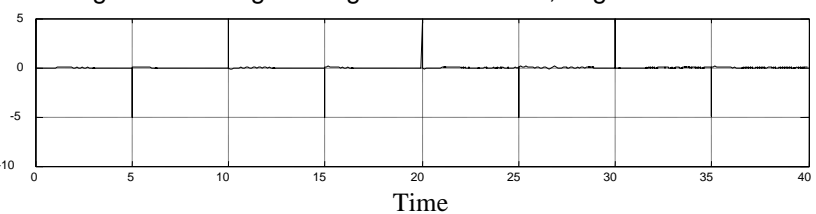

Fig. 11-f: Error between Angle of attack and Reference model Angle of

\begin{tabular}{|l|l|l|l|l|l|l|l|l|}
\multicolumn{7}{|c|}{ attack. de } & & \\
\hline
\end{tabular}

Fig. 11-g: Change in error between output and reference model, deg./sec

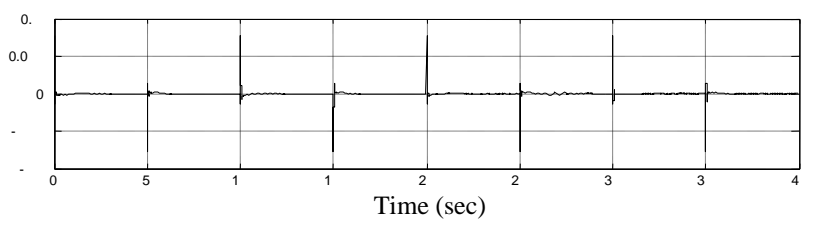

Fig. 11. Responses without Sensor Noise 
Fig. 12-a: Angle of attack and desired Angle of attack

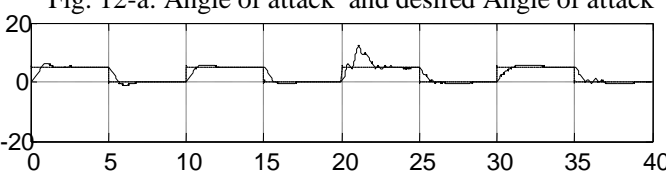

Fig. 12-b: Elevator deflection, output of controller

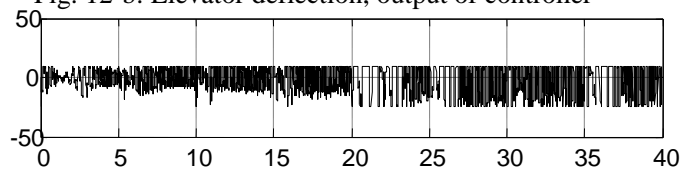

Fig. 12-c: Fuzzy inverse model output (indicate adaptation)

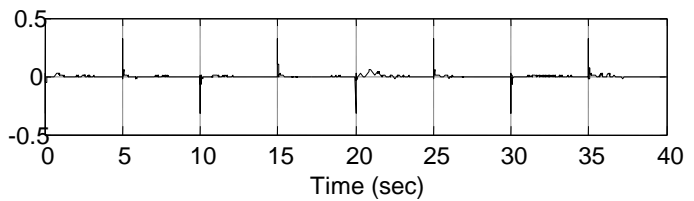

Fig. 12-d: Error between Angle of attack and desired Angle of attack

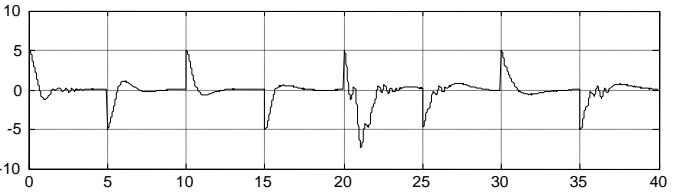

Fig. 12-e: Change in Angle of attack error, deg./sec

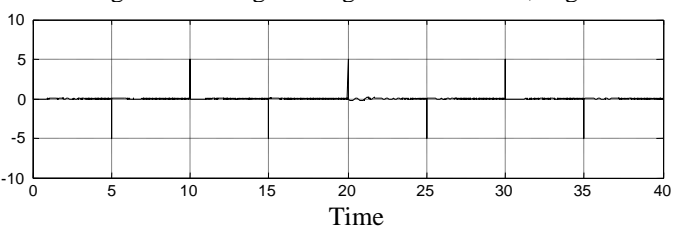

Fig.12-f: Error between Angle of attack and reference model, deg.

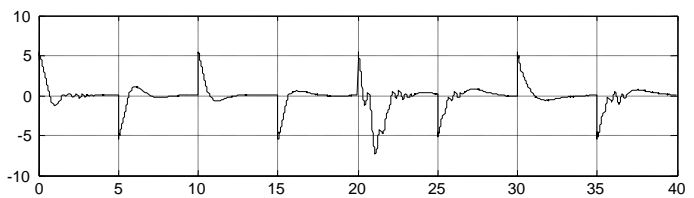

Fig. 12-g: Change in error between output and reference model, deg./sec

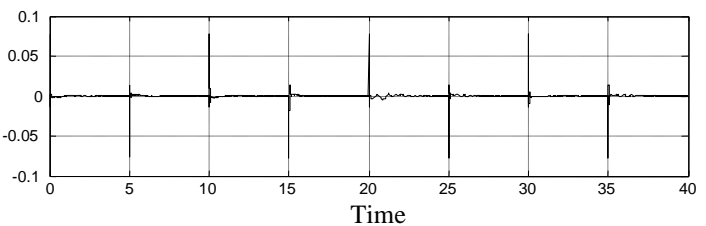

Fig. 12. Responses with Sensor Noise

2) Case-II: Simulation with Sensor Noise: In this case the pulse duration is also 40 seconds for the reference model. A random noise $0.01 \frac{\pi}{180}(2 *$ rand -1$)$ is added uniformly with the Angle of attack to 18 erify the adaptive nature of the controller. Figure 12 depicts the results of the simulation of all the parameters of Figure 11 in presence of the noise and it is clear that controller is noise adaptive.

\section{F. Control Surface}

Figures 13 and 14 shows the control surfaces [5] of AFLC without and with sensor noise, respectively. It reveals from figure that the control surface is non-linear in nature. This non-linearity nature of control surface changes with change in system parameters and is indicated by the angle of attack error and change in angle of attack error.

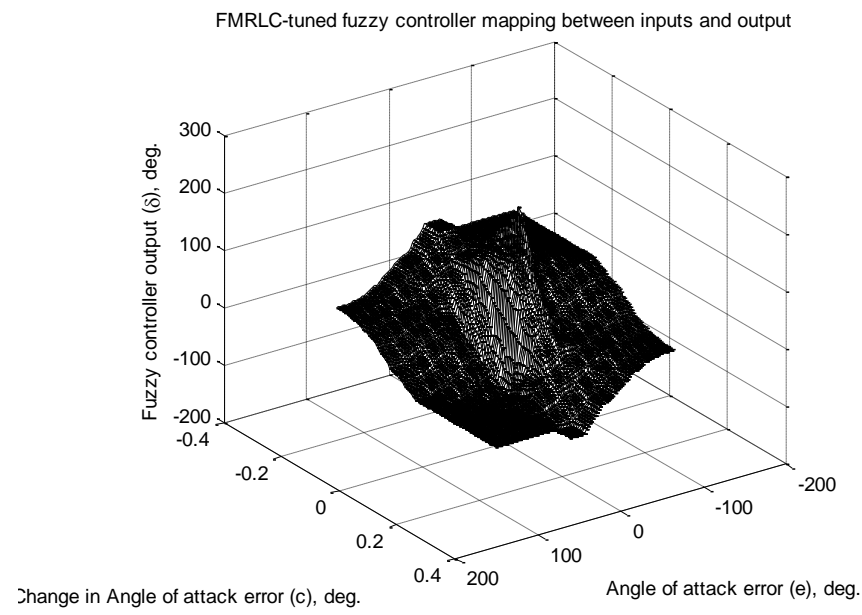

Fig. 13. Control Surface Without Sensor Noise

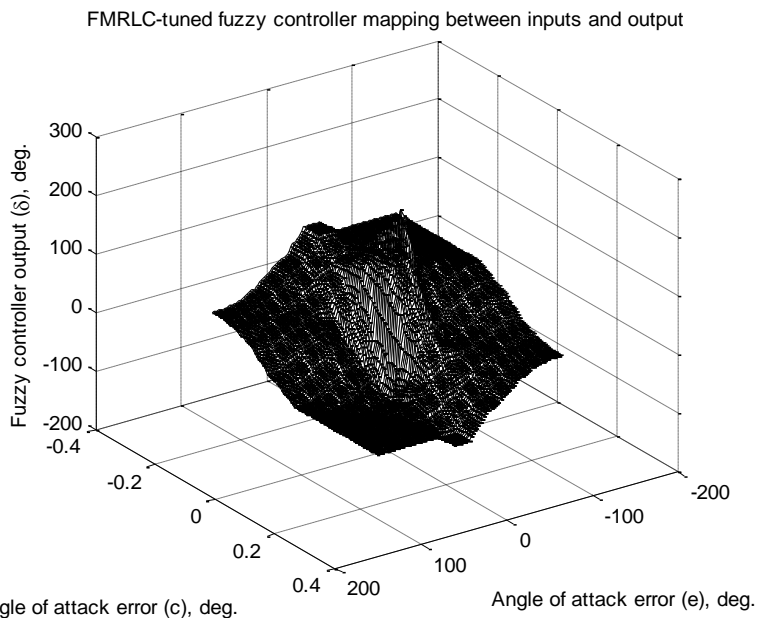

Fig. 14. Control Surface With Sensor Noise

\section{G. Performance Indices}

The performance indices of the system are given by

$$
\begin{gathered}
I A E=\int_{0}^{\infty}|e(t)| d t, M S E=\frac{1}{T} \int_{0}^{\infty} e^{2}(t) d t, I A T E=\int_{0}^{\infty} t|e(t)| d t \\
\text { where, the control error, } e=\alpha-\delta_{E}
\end{gathered}
$$

The performance indices of Zeigler Nichols Controller, Tyreus Luyben Controller, Extended Skogestad Internal Model Controller and Adaptive Fuzzy Learning Controller are compared to establish the superiority of adaptive fuzzy controller over other three controllers. It was also established that AFLC gives better results as depicted in Table 6 below. 
TABLE VI. PERFORMANCE INDICES OF ZN, TL, ESIMC AND AFLC

\begin{tabular}{|l|l|l|l|}
\hline \multirow{2}{*}{ Controllers } & \multicolumn{3}{|l|}{ Performance Indices } \\
\cline { 2 - 4 } & MSE & IAE & IATE \\
\hline ZN & 0.1311 & 57.3971 & 63.0637 \\
\hline TL & 0.1256 & 53.4471 & 30.6712 \\
\hline ESIMC & 0.0973 & 27.3914 & 1.9471 \\
\hline AFLC & 0.0698 & 19.3787 & 1.1146 \\
\hline
\end{tabular}

\section{CONCLUSION}

In this paper, the angle of attack of the aircraft is controlled using various techniques and the results are depicted in Figures 3, 4, 5, 6, 11 and 12. Also the performance indices of the system are compared as shown in Table 5 above. It reveals that AFLC adapts the change in flight conditions from FC-1 to FC-2 and gives excellent results, improves the performance indices and reduces the errors. The performance indices MSE, IAE and IATE are very less as compared to $\mathrm{ZN}$, TL and ESIMC controllers. The proposed controller not only tracks the desired angle of attack but also noise adaptation. In case of noisy input (Figure 12-b) the nonzero values of the controller output indicates that the controller continuously sends the output which nullifies the error to track the desired angle of attack. Therefore, AFLC can also be applied to other dynamic systems for its better performance and output.

\section{REFERENCES}

[1] W. Gracey, "Summary of methods of measuring angle of attack on aircraft. NACA Technical Note (NASA Technical Reports), ( NACATN-4351), pp. 1-30, 1958.

[2] C. Grimholt, "Verification and improvement of SIMC method for PI control, Technical report, Department of Chemical Engineering, Norwegian University of Science and Technology, 2010.

[3] M. Shamsuzzoha and S. Skogestad, "The setpoint overshoot method: a simple and fast method for closed loop PID tuning, Journal of Process Control, vol. 20(10)pp. 1220-34, 2010.
[4] S. Yordanova and E. Haralanova, "Design and implementation of robust multivariable PI like fuzzy logic controller for aerodynamic plant, IJAIP, vol. 3(4), pp. 257-272, 2011.

[5] D. McLean, Automatic Flight Control System, Prentice Hall International Ltd, UK, 1990.

[6] F. Dimeas and N. Aspragathos, "Fuzzy Learning Variable Admittance Control for Human Robot Cooperation, IEEE/RSJ International Conference on Intelligent Robots and Systems, pp. 4770-4775, 2014.

[7] I. S. Baruch and S. Hernandez, "Decentralized Direct I-Term Fuzzy Neural Control of an Anaerobic Digestion Bioprocess Plant, IEEE Symposium on Computational Intelligence in Control and Automation, pp. 36-43, 2011.

[8] Ruey-Jing Lian, “Adaptive Self-Organizing Fuzzy Sliding Mode Radial Basis Function Neural Network Controller for Robotic Systems, IEEE Transactions on industrial electronics, vol. 61(3), pp. 1493-1503, 2014.

[9] S. Kamalasadan and A.A. Ghandakly, "A Neural Network Parallel Adaptive Controller for Fighter Aircraft Pitch-Rate Tracking,"IEEE Transactions on Instrumentation and Measurement, vol. 60(1), pp. 258267, 2011.

[10] Huazhang Huang and Chi-Yung Chung, "Adaptive Neuro-Fuzzy Controller for static VAR Compensator to damp out wind energy conversion system oscillation, IET Generation, Transmission \& Distribution, vol. 7(2), pp. 200-207, 2013.

[11] Lusu Guoa and L. Parsa, "Model Reference Adaptive control of FivePhase IPM Motors Based on Neural network", IEEE Transactions on Industrial Electronics, vol. 59(3), pp. 1500-1508, 2012.

[12] Dawood Amoozegar," DSTATCOM modeling for voltage stability with fuzzy logic PI current controller, International Journal of Electrical Power and Energy, vol. 76, pp. 129-135, 2016.

[13] K. Premkumar, B.V. Manikandan, "Adaptive neuro-fuzzy inference system based speed controller for brushless DC motor, Neuro Compt. Journal, vol. 138, pp. 260-270, 2015.

[14] E.A. Ramadan, M. El-bardini and M.A. Fkirin, "Design and FPGAimplementation of an improved adaptive fuzzy logic controller for DC motor speed control, Ain Shams Eng. Journal, vol. 5(3), pp. 803-816, 2014.

[15] A. Fereidouni, M.A.S. Masoum and M. Moghbel, "A new adaptive configuration of PID type fuzzy logic controller, ISA Trans., vol. 56, pp. 222-240, 2015

[16] J. Yoneyama, "Nonlinear control design based on generalized TakagiSugeno fuzzy systems, Journal of Franklin Inst., vol. 351(7), pp. 35243535, 2014. 